\title{
Precision, Repeatability, and Efficiency of Two Canopy-Cover Estimate Methods in Northern Great Plains Vegetation
}

\author{
Amy J. Symstad, ${ }^{1}$ Cody L. Wienk, ${ }^{2}$ and Andy D. Thorstenson ${ }^{3}$ \\ Authors are ${ }^{1}$ Research Ecologist, Black Hills Station, Northern Prairie Wildlife Research Center, US Geological Survey, Hot Springs, SD 57747, USA; \\ ${ }^{2}$ Regional Fire Ecologist, Midwest Regional Office, National Park Service, Omaha, NE 68120, USA; and ${ }^{3}$ Lead Monitor, Northern Great Plains Fire \\ Management Office, National Park Service, Hot Springs, SD 57747, USA.
}

\begin{abstract}
Government agencies are subject to increasing public scrutiny of land management practices. Consequently, rigorous, yet efficient, monitoring protocols are needed to provide defensible quantitative data on the status and trends of rangeland vegetation. Rigor requires precise, repeatable measures, whereas efficiency requires the greatest possible information content for the amount of resources spent acquiring the information. We compared two methods—point frequency and visual estimate—of measuring canopy cover of individual plant species and groups of species (forbs vs. graminoids, native vs. nonnative) and plant species richness. These methods were compared in a variety of grassland vegetation types of the northern Great Plains for their precision, repeatability, and efficiency. Absolute precision of estimates was similar, but values generally differed between the two sampling methods. The point-frequency method yielded significantly higher values than the visual-estimate method for cover by individual species, graminoid cover, and total cover, and yielded significantly lower values for broadleaf (forb + shrub) cover and species richness. Differences in values derived by different sampling teams using the same method were similar between methods and within precision levels for many variables. Species richness and median species cover were the major exceptions; for these, the point-frequency method was far less repeatable. As performed in this study, the visual-estimate method required approximately twice the time as did the point-frequency method, but the former captured $55 \%$ more species. Overall, the visual-estimate method of measuring plant cover was more consistent among observers than anticipated, because of strong training, and captured considerably more species. However, its greater sampling time could reduce the number of samples and, therefore, reduce the statistical power of a sampling design if time is a limiting factor.
\end{abstract}

\section{Resumen}

Las agencias de gobierno están sujetas a incrementar el escrutinio público de las prácticas de administración de suelos. Por consiguiente, los protocolos de monitoreos rigurosos, pero eficientes, son necesarios para proveer datos cuantitativos defendibles sobre el estado y tendencias de los pastizales. El rigor requiere medidas repetibles y precisas, mientras que la eficiencia requiere el mayor contenido informativo por la cantidad de recursos utilizados para adquirir la información. Nosotros comparamos dos métodos-frecuencia de puntos y estimado visual-de medición de cobertura de dosel de especies de plantas individuales y grupos de especies (arbustos vs. gramíneas, nativas vs. no nativas), tan bien como la riqueza de especies de plantas. Estos métodos fueron comparados en una variedad de tipos de pastizales en las grandes llanuras del norte para su precisión, repetibilidad y eficiencia. La precisión absoluta de estimaciones fue similar, pero los valores generalmente difirieron entre los dos métodos de muestreos. El método de frecuencia de puntos produjo valores significativamente más altos que el método visual de estimación para la cobertura de especies individuales, la cobertura de gramíneas, y la cobertura total; y valores significativamente más bajos para la cobertura del mesófila (herbácea + arbusto) y la riqueza de especies. Las diferencias en valores derivados por los diferentes equipos de muestreo usando el mismo método fueron similares entre métodos y dentro de los niveles de precisión para muchas variables. La riqueza de especies y la media de la cobertura de especies fueron las excepciones mayores; para estos, el método de frecuencia de punto fue muchos menos repetible. Como se presento en este estudio, el método de estimación visual requiere aproximadamente el doble de tiempo comparado con el método de frecuencia de punto, pero a su vez capturo $55 \%$ más especies. En general, el método de estimación visual de medición de cobertura fue más consistente entre los observadores que lo anticipado, debido al fuerte entrenamiento, y capturando considerablemente más especies. Sin embargo, un tiempo de muestreo más grande podría reducir el número de muestras, y por lo tanto el poder estadístico de un diseño de muestreo, si el tiempo es un factor limitante.

Key Words: grassland, observer error, plant canopy cover, point-frequency method, vegetation monitoring, visual estimates

\section{INTRODUCTION}

Research was funded by the National Park Service and the US Geological Survey.

At the time of this work, Wienk was Fire Ecologist, Northern Great Plains Fire Management

Office, National Park Service, Hot Springs, SD, USA.

Correspondence: Amy Symstad, Wind Cave National Park, 26611 US Hwy 385, Hot Springs, SD 57747, USA. Email: asymstad@usgs.gov

Manuscript received 15 January 2007; manuscript accepted 21 April 2008.
In 1959, Daubenmire lamented the lack of standardization of methods used in vegetation sampling and analysis (Daubenmire 1959). The situation has improved somewhat since then, partially because many have adopted Daubenmire's described methodology. However, there is not now, and likely never will be, a standard method of sampling vegetation because the most 
appropriate method for measuring the relative abundance (i.e., canopy cover, projected foliar cover, basal cover, density, biomass, or frequency) of species in a plant community depends on the objective of the project for which the measurements are done and on the type of vegetation being measured (Klimeš 2003; Herrick et al. 2005). The advantages and disadvantages of each method must be weighed carefully when deciding on which method will be used.

Measuring plant cover is one of the most common ways of quantitatively describing vegetation. Its speed and low impact on the area sampled, compared with harvesting biomass, and better capture of plant size, compared with subplot frequency, make this approach preferable in many circumstances. However, the three primary methods for measuring cover-line intercept, point frequency, and visual estimate-each have their own significant advantages and disadvantages. The lineintercept method is more suited to vegetation dominated by shrubs or bunchgrasses than to vegetation in which species intermingle, such as grasslands, where rhizomatous species are common (Hanson 1950). Point frequency and visual estimates, on the other hand, are suited to most vegetation types (Elzinga et al. 1998).

Determining the balance of advantages and disadvantages for a particular method is especially important when designing a long-term monitoring program because there is a great cost, in terms of continuity of data, to changing methods midstream. Also, long-term monitoring must be sensitive to relatively subtle changes over time-time in which the observers doing the measuring will change. Thus, a method must have high repeatability among observers. Finally, the method must be efficient enough that a useful amount of data can be collected in a reasonable time, allowing for sample sizes large enough to provide the desired statistical power within funding limitations (Caughlan and Oakley 2001). Repeatability and statistical power together determine how defensible the data are in the scientific and management arenas. This is particularly important to agencies that are subject to increasing public scrutiny of management practices on public lands.

In this context, we compared the canopy cover and richness values, as well as their precision, repeatability, and efficiency, of two common methods of measuring plant cover-point frequency and visual estimates-in herb-layer vegetation of North America's northern Great Plains. Previous comparative studies have produced a variety of results for these two methods, although none, to our knowledge, addressed all of the factors mentioned above. Some authors have found greater cover values when using the point-frequency method (Bråkenhielm and Liu 1995; Vanha-Majamaa et al. 2000), but others found no significant difference (Stohlgren et al. 1998) or found different results depending on the life form being sampled (Floyd and Anderson 1987). On the other hand, methods using quadrats, as visual-estimate methods do, consistently yield larger species richness values than methods using points or lines (Stampfli 1991; Stohlgren et al. 1998; Kercher et al. 2003; Prosser et al. 2003). Few authors have compared the precision of the two methods, although Bråkenhielm and Liu (1995) found their visual-estimate method to have greater precision than a point-frequency method in sparse bog and forest vegetation. Repeatability has been the subject of a variety of studies, and methods relying on visual estimates have received particular scrutiny because of their reputation for observer bias (Klimeš 2003). Gotfryd and Hansell (1985) found highly significant differences among four observers in 18 of 20 habitat variables, including visually estimated ground cover in a Canadian forest, and Cheal (2008) demonstrated large differences among observers in projected foliar cover estimation of a bunchgrass in an Australian woodland. Klimeš (2003) found the variation in observers' visual estimates of total plant cover decreased with increasing plot size, from a coefficient of variation of $35-45 \%$ at the smallest scales $\left(0.001-0.016 \mathrm{~m}^{2}\right)$ to just 7$15 \%$ at the largest scales $\left(0.06-4 \mathrm{~m}^{2}\right)$. Kercher and colleagues (2003) found relatively high repeatability of visual estimates of total cover between two teams $(r=0.92)$ in wet meadows, and Helm and Mead (2004) found no substantial differences between point frequency and visual estimates of cover in Alaskan forests. Some authors have found point-frequency sampling to take two to six times longer than visual-estimate methods (Stampfli 1991; Prosser et al. 2003), but these differences in efficiency strongly depend on the number and arrangement of points used. Based on these results, we expected the point-frequency method to yield greater values for cover, capture fewer species, and take slightly longer than the visual-estimate method but for the two methods to be similarly repeatable. We also expected differences between methods to be similar among a variety of northern Great Plains vegetation types.

\section{METHODS}

We conducted our study to develop the vegetation monitoring protocol for a cooperative monitoring effort of the US National Park Service (NPS) Inventory and Monitoring (I\&M) and Fire Ecology programs in the northern Great Plains. The Northern Great Plains Fire Ecology Program has been collecting vegetation data in 10 NPS units since 1997, using standard NPS protocols (US Department of the Interior, National Park Service 2003) to assess changes in vegetation following prescribed fire. The northern Great Plains I\&M network is one of 32 networks in a new national program designed to monitor the ecosystem health of all NPS units with significant natural resources. Together, the programs will monitor vegetation in 13 NPS units in Nebraska, South Dakota, western North Dakota, and eastern Wyoming.

\section{Study Area}

The herb-layer vegetation in the study area is graminoid dominated, even in areas with significant tree canopy cover (e.g., ponderosa pine [Pinus ponderosa C. Lawson] forest) or shrub occurrence. The exceptions to this rule are in black-tailed prairie dog (Cynomys ludovicianus Ord 1815) towns and, sometimes, in badlands vegetation, where forbs are dominant.

Because of time constraints, we worked in only 5 of the 13 units served by the I\&M and Fire Ecology programs. We deliberately chose the units to represent the range of conditions in the geography (Table 1), ecology, and vegetation to be monitored. Agate Fossil Beds National Monument (AGFO), in western Nebraska (lat $42^{\circ} 25^{\prime} \mathrm{N}$, long $103^{\circ} 44^{\prime} \mathrm{W}$ ), and Fort Laramie National Historic Site (FOLA), in southeastern Wyoming (lat $42^{\circ} 33^{\prime} \mathrm{N}$, long $104^{\circ} 33^{\prime} \mathrm{W}$ ), were the southernmost units sampled. Vegetation at AGFO comprises rolling 
Table 1. Number of sample locations in each vegetation type for each park unit. ${ }^{1}$

\begin{tabular}{|c|c|c|c|c|c|c|}
\hline Vegetation type & AGFO & DETO & FOLA & THRO & WICA & Total \\
\hline Riparian herbaceous wetland & $5(2)$ & & & & & $5(2)$ \\
\hline Grassland & $6(1)$ & & $6(0)$ & & $4(0)$ & $16(1)$ \\
\hline Prairie dog town & & $1(0)$ & & & $2(1)$ & $3(1)$ \\
\hline Ponderosa pine forest & & $3(1)$ & & & $4(2)$ & $7(3)$ \\
\hline Shrubland & & & & $4(1)$ & $1(1)$ & $5(2)$ \\
\hline Riparian forest & & $1(1)$ & $1(0)$ & $1(0)$ & $1(0)$ & $4(1)$ \\
\hline Badlands & & & $1(0)$ & $5(1)$ & & $6(1)$ \\
\hline Total & $11(3)$ & $5(2)$ & $8(0)$ & $10(2)$ & $12(4)$ & $46(11)$ \\
\hline
\end{tabular}

${ }^{1}$ AGFO indicates Agate Fossil Beds; DETO, Devils Tower; FOLA, Fort Laramie; THRO, Theodore Roosevelt; and WICA, Wind Cave. Numbers in parentheses indicate the number of sites within each park-vegetation type combination that were double-sampled for examining repeatability.

prairie and herbaceous riparian vegetation along the Niobrara River. Before its designation as a national monument in 1965, most of the area within the park boundaries was grazed by cattle, and small portions along the river were hayed, cultivated, or used as corrals. Since then, large herbivore use has been limited to that of free-roaming white-tailed (Odocoileus virginianus Zimmermann, 1780) and mule (Odocoileus hemionus Rafinesque, 1817) deer and pronghorn (Antilocapra americana Ord, 1815). Some previously cultivated areas have been planted with native species. In general, upland vegetation is relatively free of exotic species, and riparian vegetation is dominated by exotic, sometimes invasive, species. FOLA has a long history of human occupation and livestock use, with most of its upland areas having been previously cultivated or severely grazed before park establishment in 1938. Planting of native species in upland areas has been variously successful. Herblayer vegetation in hardwood forests along the North Platte and Laramie rivers, which converge in the park, is dominated by exotic perennial grasses, although some open sand bars with sparse native vegetation do exist. Most of the 377-ha park currently serves as winter (September-April/May) pasture for varying numbers (6-32) of domestic horses. Wind Cave National Park (WICA), in southwestern South Dakota (lat $43^{\circ} 36^{\prime} \mathrm{N}$, long $\left.103^{\circ} 26^{\prime} \mathrm{W}\right)$, and Devils Tower National Monument (DETO), in northeastern Wyoming (lat $44^{\circ} 35^{\prime} \mathrm{N}$, long $\left.104^{\circ} 43^{\prime} \mathrm{W}\right)$, are in the Black Hills and, consequently, have greater precipitation than the other units $(444 \mathrm{~mm}$ vs. $364 \mathrm{~mm}$ ). Both parks were established in the early 1900s, and neither has been grazed by cattle since then. Uplands in both have largely intact native vegetation in ponderosa pine forest, prairie dog towns, and prairie, although Kentucky bluegrass (Poa pratensis L.) is common in both parks. Herblayer vegetation in the riparian forest at WICA is also dominated by native species, with a higher shrub component than at DETO, where exotic grasses and the invasive leafy spurge (Euphorbia esula L.) are dominant. Upland shrubland sampled at WICA is dominated by mountain mahogany (Cercocarpus montanus Raf.). Grazing at DETO is limited to free-roaming deer, pronghorn, and occasional elk (Cervus elaphus Linnaeus, 1758). Bison (Bison bison Linnaeus, 1758), pronghorn, and elk were reintroduced to WICA in 1911; since then, bison and elk herds have been managed at 350-500 animals each, year-round, in the 11 455-ha park, and deer and pronghorn have not been managed within the park. The south unit of Theodore Roosevelt National Park (THRO), in western
North Dakota (lat $46^{\circ} 55^{\prime} \mathrm{N}$, long $103^{\circ} 31^{\prime} \mathrm{W}$ ), was the northernmost unit we sampled. Its vegetation is highly heterogeneous; sparse badlands vegetation, mixed-grass prairie, hardwood draws, and juniper forests are intermixed in the rough upland landscape, but we focused on badlands, shrubland, and forested riparian vegetation at this park. Exotic species are rare in the badlands vegetation but are more common in the shrublands. As at most other sites, the herb layer of riparian forest is often dominated by exotic grasses and invasive forbs. Shrubland sampling at THRO concentrated on silver sagebrush (Artemisia cana Pursh.) on floodplain terraces. Before NPS acquisition, the area was used extensively, and at times intensively, for cattle ranching. Free-ranging, year-round herds of bison and elk were reintroduced to this 18 688-ha unit in 1956 and 1985, respectively. The bison herd is maintained at 200-400 animals, whereas the elk herd has increased from 47 in 1985 to approximately 525 in 2005, with two reductions of approximately 200 animals in 1993 and 2000 (Sargeant and Oehler 2007). Feral horses (70-110) also occupy the area yearround.

\section{Sampling}

Sampling sites within park units were located randomly within the broad vegetation classes of grassland, herbaceous riparian, forested riparian, prairie dog town, ponderosa pine forest, shrubland, and badlands (sparse vegetation because of naturally poor soil conditions). Forty-six sites were allocated among vegetation types in rough proportion to the abundance of the vegetation types in all NPS units of this region (Table 1). A single $20 \times 50 \mathrm{~m}$ plot at each site was the sampling unit.

At each plot, canopy cover of individual species was measured twice along each of the two 50-m transects comprising the edges of the plots, once with the pointfrequency method and once with the visual-estimate method. For the point-frequency method, all species touching a $0.6-\mathrm{cm}-$ diameter pole inserted into the vegetation perpendicular to the ground were recorded at each of 100 evenly spaced points along a 50-m transect. Two observers worked together on a single transect; one observer recorded the observations of the other for the first 50 points, then roles were switched for the remaining 50 points.

For the visual-estimate method, 10 quadrats of $0.5 \times 1.0 \mathrm{~m}$ were placed at $5-\mathrm{m}$ intervals along each $50-\mathrm{m}$ transect. For each quadrat, canopy cover of all species whose foliage polygon overlapped or was wholly within the quadrat (following 
Daubenmire 1959) was visually estimated to the nearest $1 \%$. (For brevity, canopy cover is henceforth referred to as cover.) Cover classes were not used, despite their speed and common use in vegetation sampling, because of their tendency to overestimate cover of small or rare species (Floyd and Anderson 1987) and because of their large boundary errors (Helm and Mead 2004). Visual estimates were aided by $10-\mathrm{cm}$ increments marked on the polyvinyl chloride frames used to sample quadrats and by cards representing $2 \%$ of the area of the quadrat. As with the point-frequency method, two observers worked together on a single transect, with both making visual estimates of cover on each quadrat. Thus, the two observers had to agree on a value for each species before that cover value was recorded. Training at the beginning of the study, before any data were collected, focused on ensuring understanding of the foliage polygon method-in which the cover of an individual plant is the area within a polygon connecting the outermost points of the live leaves of an individual plant-and on obtaining consistent visual estimates of cover among all observers.

For 21 of the 46 plots, the same team of two observers used both methods on the same transect. In these cases, the team members randomly chose which method to use first. For the remainder of the plots, the visual estimate and point-frequency methods were completed by two different teams on the same transect. After completing the cover measurements, all observers worked together to compile a thorough list of all species occurring within the 0.1-ha plot.

Eleven plots were double-sampled to compare the repeatability of measurements between observers for the two coverestimate methods (Table 1). When a plot was designated for double sampling, the first observers to sample the plot left plot markers in place (at the four corners of the plot), but they removed all tapes indicating transect locations. A second group of observers relocated and sampled the plot following the methods described above. Before they finished sampling the plot, the second observers did not discuss the plot with the first team. Most double-sampling was completed within $36 \mathrm{~h}$ of the original sample, although two second samples occurred $6 \mathrm{~d}$ after the original sample. Composition of two-person teams was purposely varied throughout the study, and 10 observers with a variety of skill levels comprised the work crew; these conditions are those expected when the long-term monitoring program is implemented. All sampling occurred in June and July of 2005.

\section{Data Analysis}

Except for analyses specifically focusing on repeatability, we used only the values obtained in the first sampling of a doublesampled plot. Preliminary analyses showed that results were not affected by whether the same or different subteams completed the two sampling methods in an individual plot. Thus, we made no distinction between these two situations in analyses.

Analyses concentrated on five community-level and three species-level response variables relevant to the long-term monitoring program. The community-level variables were total cover, graminoid cover, broadleaf (forb and shrub) cover, exotic percentage of cover, and species richness. The species- level variables were the cover of the first and second mostabundant species in a plot, as representatives of dominant and subdominant species, respectively, and the cover of the species with the median cover level in that plot, as a representative of the majority of species.

For the point-frequency method, we calculated cover of individual species as the percentage of 200 points at which a species occurred, and we calculated cover of plant types (e.g., exotic, native, graminoid, forb) as the sum of the cover of the species in that category at that plot level. Total plant cover was the sum of cover values for all species, and species richness was the number of species encountered at all points. For the visualestimate method, we calculated values of cover variables for each quadrat, then averaged those values over the 20 quadrats to obtain plot-level values. Species richness was the number of species encountered in all quadrats.

For the eight response variables, we compared values obtained by the two methods and evaluated repeatability of the two methods at the plot level with correlation analyses and paired $t$ tests. We compared repeatability of plot-level composition by calculating the Bray-Curtis (Bray and Curtis 1957) and Morisita-Horn (Horn 1966) similarity indices between the two samples of each method for each plot. The Bray-Curtis index is more sensitive to species richness, whereas the Morisita-Horn index is more sensitive to the abundance of the most abundant species (Magurran 1988). A paired $t$ test, in which each plot was a sample, was used to compare the compositional similarity of the teams between sampling methods.

Compositional similarity indices are sensitive to species pseudoturnover, in which one team records a species that the other does not. Species pseudoturnover is defined as

$$
\text { Species pseudoturnover }=\left[(A+B) /\left(S_{A}+S_{B}\right)\right] \times 100[1]
$$

where $A$ and $B$ are the number of exclusive species found by Team A and Team B, respectively, and $S_{A}$ and $S_{B}$ are the total number of species found by Team A and Team B, respectively (Nilsson and Nilsson 1985). We calculated species pseudoturnover for each sampling method in each double-sampled plot then compared the values between sampling methods with a paired $t$ test.

In the analyses above, we combined data from all vegetation types for a variety of reasons. First, the goal of this study was to develop one sampling method that could be used in a variety of vegetation types, because the vegetation type of a permanent plot may change over the time of long-term monitoring. Second, comparisons of values, and particularly the correlation between them, is best examined over the widest range of values possible, which we achieved by combining vegetation types. Finally, we did not have large enough sample sizes within individual vegetation types to make valid statistical comparisons for repeatability.

Differences in cover and species richness among vegetation types, however, are likely to cause variation in precision and time to complete. Thus, we determined the precision of the estimates of six response variables (graminoid and broadleaf cover excluded for brevity) for each vegetation type and overall with the Power procedure (one-sample confidence interval option) in SAS (SAS 2004). Precision was defined as one half the 
width of the $90 \%$ confidence interval, with $\beta=0.10$. Subsamples in the visual-estimate method were individual $0.5-\mathrm{m}^{2}$ quadrats, whereas subsamples in the point-intercept method were 10 consecutive points. This division yielded 20 subsamples, each representing a 5 -m segment of a transect, at each plot, for both methods; from these, we calculated the standard deviation of each response variable. For each response variable, we used the average standard deviation (from 3-16 plots for individual vegetation types; 46 plots overall) to estimate the precision level attainable with 20 subsamples for each response variable.

For each vegetation type, we compared the efficiency of the two methods with Student's $t$ tests, using the amount of time spent sampling each plot with each sampling method and the species-capture efficiency (number of species recorded in the cover method as a percentage of species from 0.1-ha plot species list) as response variables. We used linear regression to investigate the relationship between time for completion or species capture and plot species richness or total cover for each method. For this analysis, we did not separate among vegetation types so as to incorporate the full range of species richness and total cover. We constructed species-subsample number curves using EstimateS 7.5 (Colwell 2005) for the plots with highest and lowest plot species richness in each vegetation type to determine the approximate return in greater species capture by adding subsamples.

Finally, because rarer species are often of management concern, either as newly occurring exotic species or as species more sensitive to management practices (e.g., high ungulate abundance, invasive species control), we investigated the difference between the two methods in their detection and precision of estimating the cover of less abundant species. The precision with which the visual-estimate method measured the cover of the species missed by the point-frequency method was estimated using the standard deviation of the visual-estimate cover of species with $1 \%$ and $5 \%$ cover (values representing two separate thresholds for species detection) in each plot. Because rank-abundance patterns were similarly variable among plots within the different vegetation types (Symstad et al. 2006), we did not perform this analysis separately by vegetation type. We used SAS version 9.1 for Windows (SAS 2004) for all statistical analyses and set statistical significance at $\alpha=0.05$.

\section{RESULTS}

\section{Comparison of Values Between Methods}

The values from the two methods were significantly correlated for all variables, with the correlation being strongest for broadleaf cover and exotic percentage of cover (Fig. 1). However, the two sampling methods yielded significantly different values for seven of the eight response variables, exotic percentage of cover being the exception (Fig. 1). The pointfrequency method yielded higher values for cover, whereas the visual-estimate method yielded higher values for species richness. The greatest discrepancies between methods were in median species' cover and in species richness, whereas the smallest discrepancies were in broadleaf cover and exotic percentage of cover.
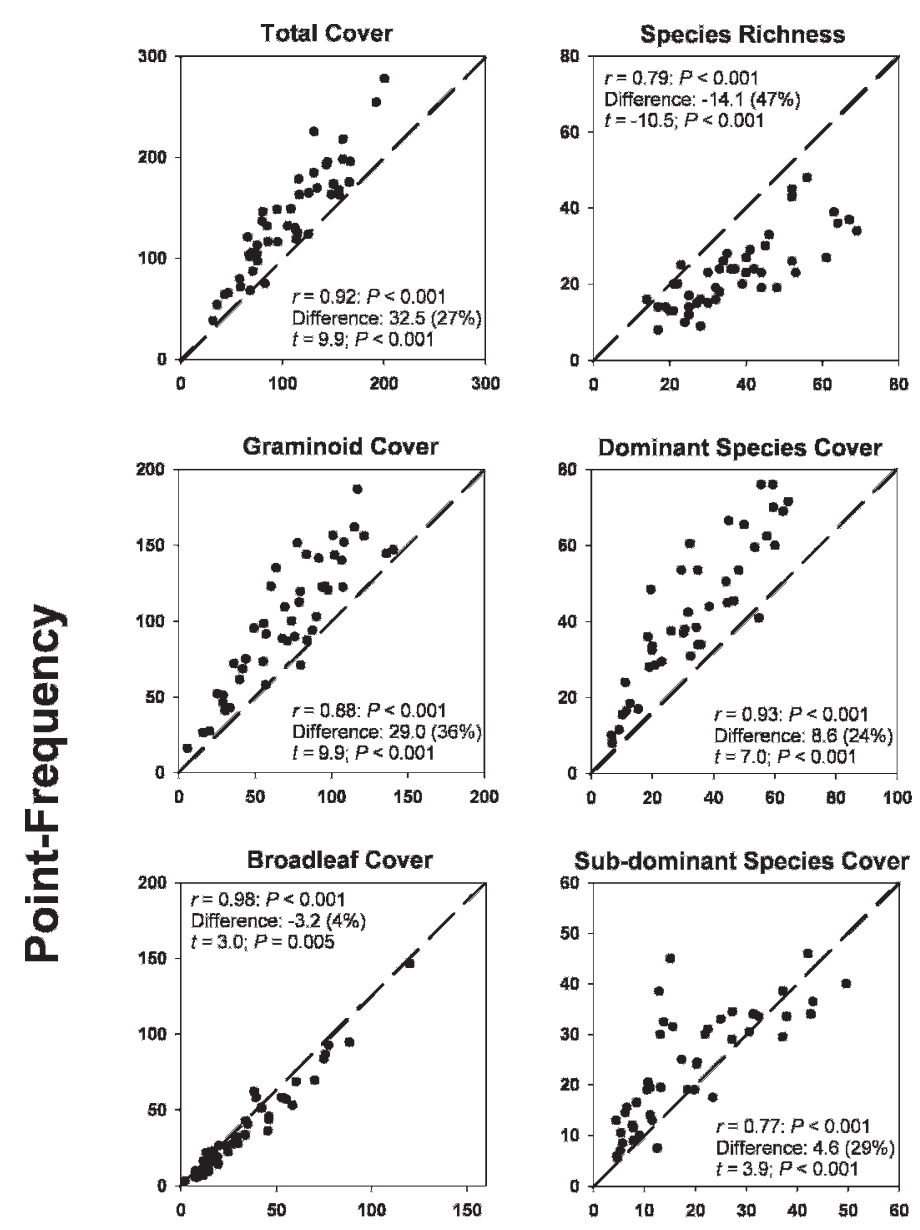

Sub-dominant Species Cover

言
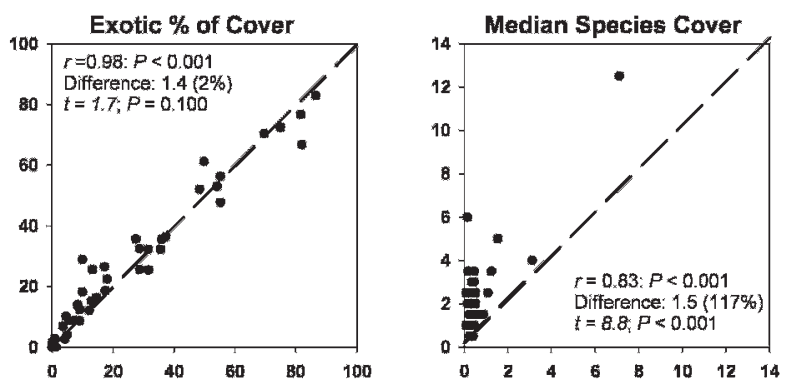

\section{Visual Estimate}

Figure 1. Comparison of values obtained using point-frequency vs. visual-estimate sampling methods for eight response variables. Units of cover are percentages. Correlation and Student's $t$ test results are shown for each variable. "Difference" is the average difference between pointfrequency and visual-estimate values; that difference, as a percentage of the average of the two values, is shown in parentheses.

\section{Repeatability and Precision of Measurements}

For most community-level variables, correlation between the two teams was high $(r \geq 0.96)$ and highly significant for both methods (Table 2). Only for species richness did correlations between the two teams for the two methods differ substantially (visual estimate $r=0.96$ vs. point frequency $r=0.84$ ). However, the teams' values differed significantly for all communitylevel response variables (Table 2). These differences were similar between methods for all community-level response variables, except total cover, for which the point-frequency 
Table 2. Correlation and difference between values of vegetation response variables recorded by two sampling teams using point-frequency (PF) and visual-estimate methods of measuring plant canopy cover. ${ }^{1,2}$

\begin{tabular}{|c|c|c|c|c|c|}
\hline \multirow[b]{2}{*}{ Variable } & \multicolumn{2}{|c|}{ Visual estimate } & \multicolumn{2}{|c|}{ Point frequency } & \multirow{2}{*}{$\begin{array}{c}\text { Method comparison } \\
\text { PF-visual }{ }^{3}\end{array}$} \\
\hline & $r$ & $\|A-B\|$ & $r$ & $\|A-B\|$ & \\
\hline Total cover & $0.98^{* * *}$ & $5.32(2.23)^{\star}$ & $0.96^{\star * *}$ & $11.18(1.66)^{* \star *}$ & $5.86(2.38)^{*}$ \\
\hline Graminoid cover & $0.99^{* * *}$ & $4.49(1.69)^{\star}$ & $0.98^{* * *}$ & $6.73(1.46)^{\star \star}$ & $2.24(2.14)$ \\
\hline Broadleaf cover & $0.99^{* * *}$ & $2.05(0.48)^{\star *}$ & $0.99^{* * *}$ & $3.45(0.83)^{\star \star}$ & $1.41(1.00)$ \\
\hline Exotic percentage of cover & $0.99^{\star * *}$ & $1.99(0.61)^{\star *}$ & $0.99^{* * *}$ & $2.37(0.68)^{\star *}$ & $0.38(0.63)$ \\
\hline Species richness & $0.96^{\star \star \star}$ & $2.55(0.74)^{\star \star}$ & $0.84^{* * *}$ & $4.00(0.81)^{\star * *}$ & $1.46(1.05)$ \\
\hline Dominant species cover & $0.98^{* * *}$ & $4.96(1.00)^{\star * *}$ & $0.99^{\star * *}$ & $3.77(0.83)^{\star *}$ & $-1.19(1.67)$ \\
\hline Subdominant species cover & $0.85^{\star * \star}$ & $4.09(1.67)^{\star}$ & $0.84^{\star * *}$ & $5.09(1.38)^{\star \star}$ & $1.00(0.79)$ \\
\hline Median species cover & $0.85^{\star * \star}$ & $0.19(0.05)^{\star \star}$ & $0.53 \dagger$ & $1.14(0.21)^{\star * *}$ & $0.95(0.23)^{\star \star}$ \\
\hline Bray-Curtis similarity & \multicolumn{2}{|c|}{$0.848(0.021)$} & \multicolumn{2}{|c|}{$0.827(0.022)$} & $-0.021(0.009) \dagger$ \\
\hline Morisita-Horn similarity & \multicolumn{2}{|c|}{$0.952(0.017)$} & \multicolumn{2}{|c|}{$0.946(0.018)$} & $-0.006(0.003) \dagger$ \\
\hline Species pseudoturnover & \multicolumn{2}{|c|}{$20.1(2.1)$} & \multicolumn{2}{|c|}{$27.2(3.5)$} & $7.12(2.73)^{\star}$ \\
\hline
\end{tabular}

${ }^{1}$ For all tests, $\mathrm{df}=10$. $\dagger$ indicates $t$ test significant at $P<0.10 ;{ }^{*}, P<0.05 ;{ }^{* *}, P<0.01$; and ${ }^{* * *}, P \leq 0.001$.

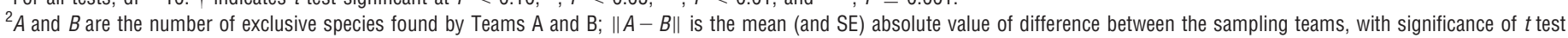
indicated for first 8 variables; mean (and SE) value for the last three variables.

${ }^{3}$ Mean (and SE) difference of between-team differences with significance of $t$ test indicated.

method had significantly greater discrepancies between teams than did the visual-estimate method.

Values of species-level response variables also differed significantly between sample teams for both methods (Table 2). Differences between teams in dominant and subdominant species cover did not differ significantly between methods, but the point-frequency method had significantly greater discrepancies between teams for median species cover. For cover of the dominant species, correlation between samples for both methods was similar to that for the community-level variables $(r \geq 0.98)$. For cover of the subdominant and median species, however, correlation was considerably lower, especially for the point-frequency method for the median species, for which there was no significant correlation between the two teams' values (Table 2).

Compositional similarity was marginally greater for the visualestimate method than for the point-frequency method when measured with either the Bray-Curtis or the Morisita-Horn similarity index (Table 2). Species pseudoturnover was substantial in most plots that were double-sampled, ranging from $6 \%$ to $57 \%$, and it was significantly higher with the point-frequency method (Table 2). Twenty percent of the species detected by one team, but not the other, had greater than $1 \%$ cover; this percentage did not differ significantly between sampling methods $($ difference $=6.75 \pm 5.91, t=1.14, \mathrm{df}=10, P=0.280$ ).

Absolute precision values were higher with the pointfrequency method in badlands, prairie dog town, and grassland vegetation for total cover; higher with the visual-estimate method for herbaceous riparian and shrubland vegetation for dominant species cover; and higher with the point-frequency method in all but forested and herbaceous riparian vegetation for median species cover. Absolute precision values were similar between the two methods for all other response variable-vegetation type combinations (Table 3). Differences in relative precision values (i.e., confidence interval width relative to the mean value) between methods varied much more among vegetation types (Table 3 ). Relative precision values were most similar between methods for prairie dog town vegetation, in which median species cover was the only variable for which precision varied substantially between methods. In ponderosa pine and shrubland vegetation, relative precision values were similar or higher with the visual-estimate method for all variables, except median species cover. Badlands vegetation was unique in that the visual-estimate method had higher relative precision values than the point-frequency method for dominant and subdominant species cover, but the opposite for exotic percentage of cover and species richness. Across all vegetation types, relative precision values were smallest for total cover and greatest for cover of individual species, with the confidence interval for median species cover being almost three times the mean value.

\section{Efficiency}

Overall, and for each vegetation type, except forested riparian, sampling time for the point-frequency method was significantly lower than for the visual-estimate method (Table 4). On average, it took $2.1 \mathrm{~h}(\mathrm{SE}=0.22 \mathrm{~h})$ longer for a two-person team to complete the sampling of two transects with the visualestimate method than with the point-frequency method. The greatest discrepancy between methods was in prairie dog towns, where the visual-estimate method took $3.6 \mathrm{~h}$ longer than the point-frequency method. Visual-estimate sampling time increased significantly with plot species richness and total plant cover, but point-frequency sampling time did not increase with plot species richness and increased only slightly with greater total cover (Fig. 2). Consequently, the difference in sampling time between the methods increased with plot species richness $\left(r^{2}=0.26, P<0.001\right)$, but not with total cover $\left(r^{2}=0.03, P=0.29\right)$.

The two methods also differed significantly in the number of species they captured overall and for all vegetation types except prairie dog towns and herbaceous riparian plots, although for the former, the low sample size $(n=3)$ made a large difference only marginally significant statistically (Table 4). On average, the point-frequency method captured only $44 \%$ of the species 
Table 3. Means and precision of measurements for six response variables from visual-estimate and point frequency methods of measuring plantcanopy cover overall $(0)$ and in each vegetation type (B indicates badlands; D, prairie dog town; F, forested riparian; $G$, grassland; $H$, herbaceous riparian; $P$, ponderosa pine forest; and $S$, shrubland). Absolute precision is one half the width of the $90 \%$ confidence interval, with $\beta=0.10$. Relative precision is absolute precision as a percentage of the mean value.

\begin{tabular}{|c|c|c|c|c|c|c|c|c|c|c|c|c|c|c|c|c|}
\hline & \multicolumn{8}{|c|}{ Visual estimate } & \multicolumn{8}{|c|}{ Point frequency } \\
\hline & 0 & B & $\mathrm{D}$ & $\mathrm{F}$ & G & $\mathrm{H}$ & $P$ & S & 0 & B & $\mathrm{D}$ & $\mathrm{F}$ & G & $\mathrm{H}$ & $\mathrm{P}$ & S \\
\hline \multicolumn{17}{|l|}{ Total cover } \\
\hline Mean & 106 & 54 & 108 & 154 & 104 & 147 & 79 & 135 & 139 & 77 & 139 & 179 & 144 & 181 & 107 & 163 \\
\hline Absolute precision & 16 & 17 & 10 & 22 & 14 & 20 & 19 & 18 & 20 & 25 & 17 & 24 & 18 & 21 & 20 & 19 \\
\hline Relative precision & 15 & 31 & 9 & 14 & 13 & 14 & 24 & 13 & 14 & 32 & 12 & 13 & 12 & 12 & 19 & 12 \\
\hline \multicolumn{17}{|c|}{ Exotic percentage of cover } \\
\hline Mean & 23 & 3 & 15 & 34 & 22 & 22 & 18 & 17 & 25 & 3 & 13 & 64 & 23 & 21 & 24 & 30 \\
\hline Absolute precision & 7 & 2 & 5 & 10 & 6 & 10 & 8 & 8 & 7 & 3 & 5 & 10 & 6 & 8 & 8 & 7 \\
\hline Relative precision & 30 & 67 & 33 & 29 & 27 & 45 & 44 & 47 & 28 & 100 & 38 & 16 & 26 & 38 & 33 & 23 \\
\hline \multicolumn{17}{|l|}{ Species richness ${ }^{1}$} \\
\hline Mean & 8 & 7 & 12 & 7 & 10 & 6 & 7 & 8 & 5 & 4 & 5 & 5 & 6 & 5 & 4 & 6 \\
\hline Absolute precision & 2 & 2 & 2 & 2 & 2 & 1 & 2 & 2 & 0.9 & 2 & 0.8 & 0.9 & 0.8 & 0.8 & 0.9 & 0.9 \\
\hline Relative precision & 24 & 30 & 17 & 27 & 20 & 16 & 28 & 24 & 17 & 48 & 15 & 16 & 14 & 17 & 22 & 16 \\
\hline \multicolumn{17}{|c|}{ Dominant species cover } \\
\hline Mean & 38 & 12 & 34 & 60 & 37 & 56 & 31 & 46 & 47 & 17 & 39 & 67 & 50 & 69 & 38 & 43 \\
\hline Absolute precision & 12 & 8 & 9 & 15 & 11 & 15 & 12 & 15 & 12 & 9 & 10 & 12 & 12 & 11 & 12 & 11 \\
\hline Relative precision & 32 & 67 & 26 & 25 & 30 & 27 & 39 & 33 & 25 & 53 & 26 & 18 & 24 & 16 & 32 & 26 \\
\hline \multicolumn{17}{|c|}{ Subdominant species cover } \\
\hline Mean & 19 & 8 & 19 & 24 & 19 & 27 & 14 & 26 & 23 & 9 & 24 & 23 & 26 & 30 & 21 & 31 \\
\hline Absolute precision & 10 & 7 & 10 & 12 & 9 & 15 & 8 & 13 & 11 & 7 & 11 & 12 & 10 & 16 & 10 & 14 \\
\hline Relative precision & 53 & 88 & 53 & 50 & 47 & 56 & 57 & 50 & 48 & 78 & 56 & 52 & 38 & 53 & 48 & 45 \\
\hline \multicolumn{17}{|l|}{ Median species cover } \\
\hline Mean & 0.6 & 0.3 & 0.4 & 0.7 & 0.4 & 2 & 0.3 & 0.3 & 2.2 & 1.6 & 1.3 & 2.0 & 2.2 & 4.7 & 1.9 & 1.2 \\
\hline Absolute precision & 0.9 & 0.6 & 0.6 & 2.0 & 0.7 & 4 & 0.5 & 0.4 & 3 & 3 & 3 & 3 & 3 & 5 & 3 & 2 \\
\hline Relative precision & 150 & 200 & 150 & 286 & 175 & 160 & 167 & 133 & 136 & 188 & 231 & 150 & 136 & 106 & 158 & 167 \\
\hline
\end{tabular}

${ }^{1}$ Note that means and precision were calculated using subsamples (quadrats for visual estimate, or 10 points for point frequency); therefore, the mean value for species richness is lower than the whole-plot value shown elsewhere.

recorded in the 0.1-ha plot, whereas the visual-estimate method point-frequency method, this method was still more efficient captured $68 \%$ of a plot's species. Species capture did not vary than the visual-estimate method in terms of the number of by plot species richness or total canopy cover (regression species captured per hour (difference $=3.05 \pm 0.89$ SE; $P>0.10)$. Despite the lower number of species captured by the $\quad t=3.43, \mathrm{df}=40, P=0.001)$.

Table 4. Comparison of species capture (percentage of number recorded in 0.1-ha plot) and time to complete between the visual-estimate and point-frequency methods overall $(0)$ and for each vegetation type separately (B indicates badlands; $D$, prairie dog town; $F$, forested riparian; $G$, grassland; $\mathrm{H}$, herbaceous riparian; $\mathrm{P}$, ponderosa pine forest; and $\mathrm{S}$, shrubland).

\begin{tabular}{|c|c|c|c|c|c|c|c|c|}
\hline & 0 & B & $\mathrm{D}$ & $\mathrm{F}$ & G & $\mathrm{H}$ & $P$ & S \\
\hline \multicolumn{9}{|c|}{ Species capture (\%), visual-point } \\
\hline Sample size & 46 & 6 & 3 & 4 & 16 & 5 & 7 & 5 \\
\hline Means (visual-point) & $68-44$ & $66-44$ & $74-44$ & $71-52$ & $69-39$ & $66-61$ & $66-35$ & $71-45$ \\
\hline$t$ & 13.4 & 4.9 & 3.5 & 3.8 & 13.1 & 0.7 & 8.4 & 9.3 \\
\hline$P$ & $<0.001$ & 0.004 & 0.07 & 0.03 & $<0.001$ & 0.54 & $<0.001$ & $<0.001$ \\
\hline \multicolumn{9}{|c|}{ Time to complete $(h)$, visual-point } \\
\hline Sample size & 41 & 5 & 3 & 4 & 12 & 5 & 7 & 5 \\
\hline Means (visual-point) & $3.8-1.9$ & $3.1-2.1$ & $4.7-1.2$ & $3.6-1.8$ & $3.9-1.8$ & $4.0-2.6$ & $4.2-1.9$ & $3.5-2.0$ \\
\hline$t$ & 9.5 & 3.4 & 6.4 & 1.8 & 5.2 & 3.2 & 5.9 & 3.1 \\
\hline$P$ & $<0.001$ & 0.03 & 0.02 & 0.16 & $<0.001$ & 0.03 & 0.001 & 0.04 \\
\hline
\end{tabular}




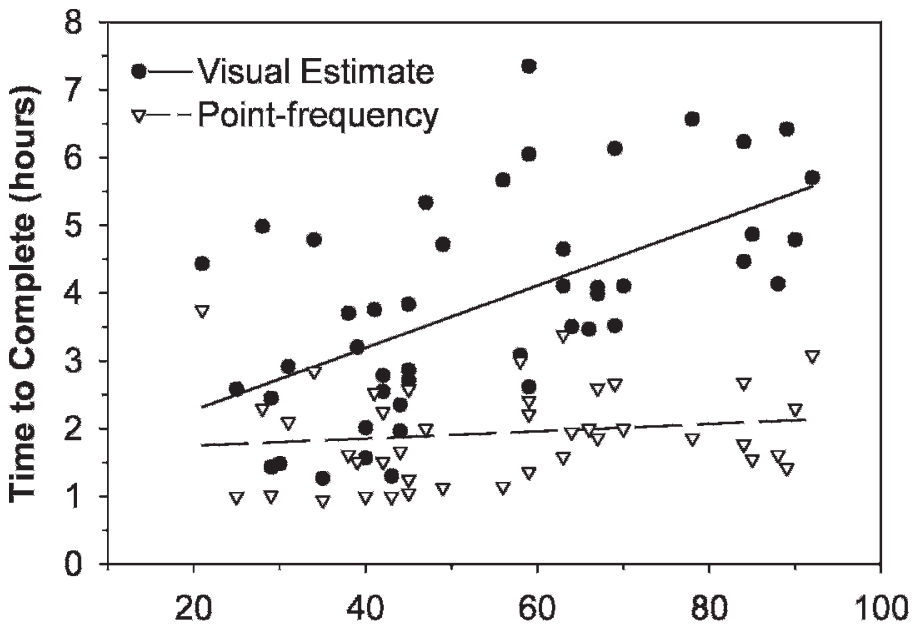

Plot Species Richness

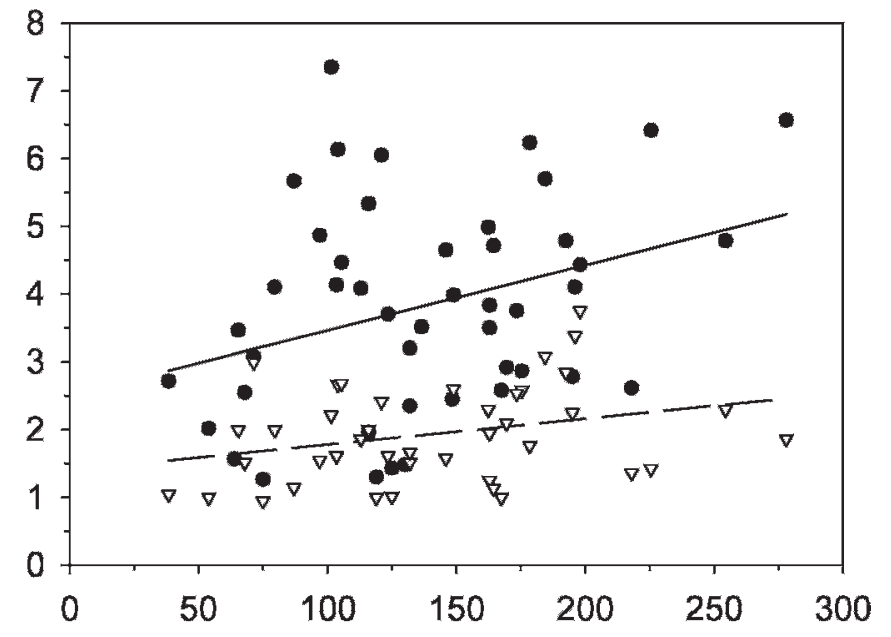

Total Plant Cover (\%) (PF method)

Figure 2. Relationship between time to complete each sampling method and plot species richness (left) or total plant cover as measured by the point-frequency (PF) method (right). Time to complete, as a function of plot species richness, by visual estimate: $y=1.36+0.046 x ; r^{2}=0.34$; $P<0.0001$; and by point frequency: $y=1.64+0.0054 x ; r^{2}=0.023 ; P=0.34$. Time to complete, as function of total plant cover, by visual estimate: $y=2.50+0.0096 x ; r^{2}=0.11 ; P=0.025 ;$ and by point frequency: $y=1.40+0.0038 x ; r^{2}=0.088 ; P=0.059$.

The shape of species-subsample curves suggests that adding more subsamples in the point-frequency method would yield fewer additional species than would adding more subsamples in the visual-estimate method (Fig. 3). Only with the visualestimate method, and only for 2 of the 14 plots for which curves were constructed, did 20 subsamples reach the point where adding more subsamples would add no more species.

In the entire study, there were 1749 species-plot combinations. In 702 instances, the point-frequency method missed a species that the visual-estimate method captured, but the average cover of these missed species (as measured by the visual-estimate method) was very low $(0.25 \%)$. In 141 instances, the visualestimate method missed a species that the point-frequency method captured; the average cover of these missed species (as measured by the point-frequency method) was $0.84 \%$. In all of these instances, cover of the missed species was $<10 \%$, and in $\geq 74 \%$ of the instances, the species' cover was $<0.5 \%$. The precision with which the visual-estimate method estimated the cover of species with $1 \%$ and $5 \%$ cover was $100-500 \%$ of the cover value, depending on vegetation type and confidence level
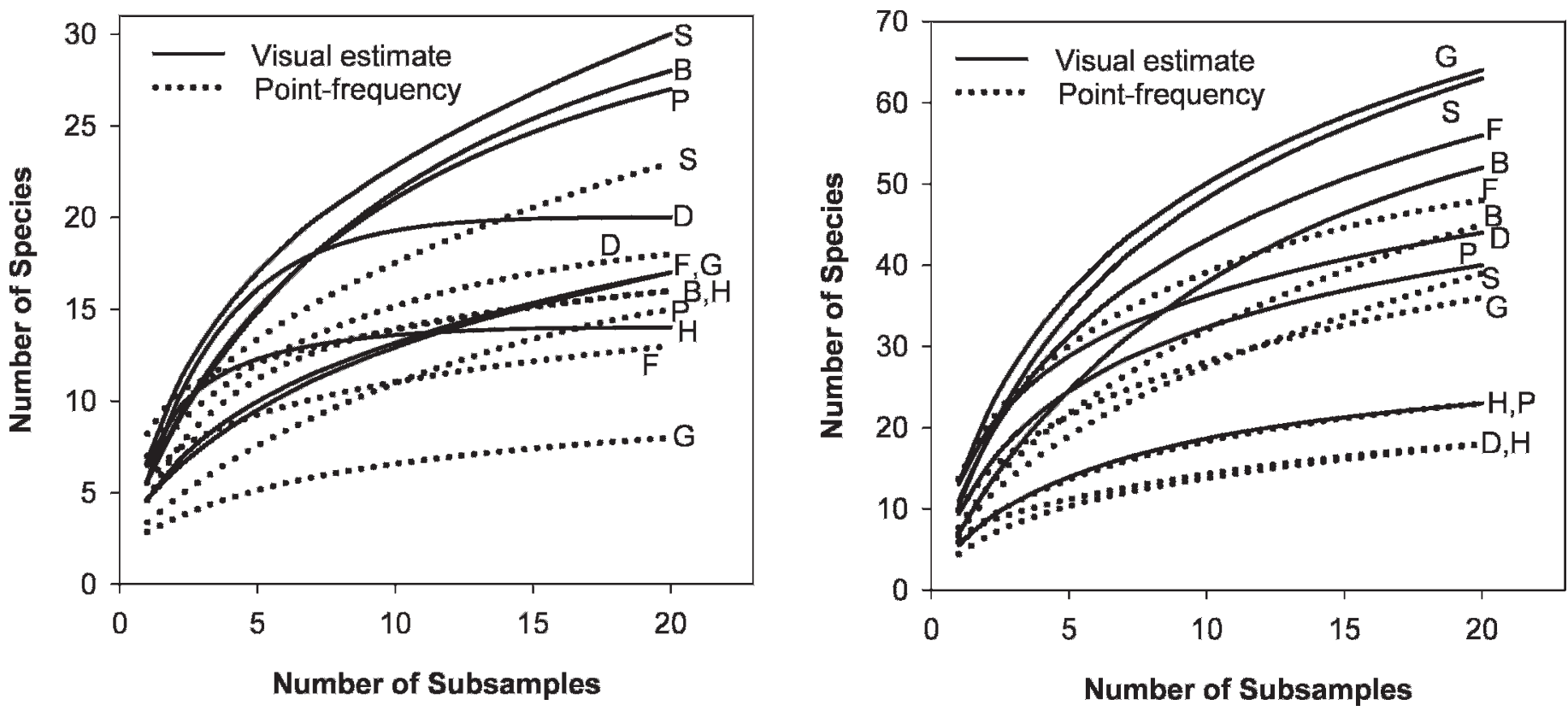

Figure 3. Species-sample number curves for plots with the lowest (left) and highest (right) species richness from each vegetation type. B indicates badlands; D, prairie dog town; F, forested riparian; G, grassland; H, herbaceous riparian; P, ponderosa pine forest; and S, shrubland. 
( $\alpha=0.05$ to $0.1, \beta \leq 0.1$ ). The ranges for number of subsamples required to attain $20 \%$ precision for species with $1 \%$ and $5 \%$ cover were 339-1426 and 94-1 015, respectively.

\section{DISCUSSION}

Our results were consistent with our expectations in only some instances. Our study yielded higher cover and lower species richness values with the point-frequency method, as expected. However, contrary to expectations, the visualestimate method was more repeatable between observers for some response variables. The magnitude of differences in relative precision and efficiency between methods did vary among the seven vegetation types we sampled, but the direction was the same in almost all cases: variability with respect to a plot's mean was greater for the visual-estimate method, and the point-frequency method required substantially less time.

\section{Comparison of Values Between Methods}

The higher cover and lower richness values obtained by the point-frequency method are consistent with other studies (Bråkenhielm and Li 1995; Vanha-Majamaa et al. 2000). In the grass-dominated vegetation in our study, the difference in cover values was due to graminoids, for which the pointfrequency value was $36 \%$ greater than the visual-estimate value (Fig. 1). In contrast, the point-frequency cover value for broadleaf species (forbs and shrubs) was $4 \%$ lower than the visual-estimate value.

It is not clear which method more accurately represents the true cover of vegetation, a value nearly impossible to determine in multilayered, diffuse vegetation like much of that in this study. The higher point-frequency cover values for graminoids was somewhat surprising because the foliage polygons used to visually estimate cover included empty spaces between grass blades. Reducing the large diameter of the "point" used in this study would likely make values from the two methods more alike.

Not knowing the accuracy of either method is not necessarily a problem for long-term monitoring as long as the sampling method is consistently applied across space and through time, and interpretation of the information takes into account the peculiarities of the sampling method used. This is especially important when the data will be used in setting and evaluating quantitative management objectives. Because some of the most abundant exotic species in the parks of this region are grasses (e.g., smooth brome [Bromus inermis Leyss.], Japanese brome [Bromus japonicus Thunb. ex Murr.], cheatgrass [Bromus tectorum L.], and crested wheatgrass [Agropyron cristatum $\{\mathrm{L}$. Gaertn.]), it could be easier to reduce cover of one of these species to a target value of $20 \%$ maximum cover if the measurement is done using the visual-estimate method rather than the point-intercept method.

The relatively high correlation between values obtained by the two methods suggests that conversion of data between the two methods, after sufficient calibration efforts, is possible. This is particularly relevant for agencies establishing new longterm monitoring programs that wish to incorporate older data from previous efforts. However, our data suggest that, whereas this conversion could be quite reliable for composite cover values, it would not be reliable for individual species' cover or for species richness.

\section{Repeatability Among Observers}

Although differences between observer teams were significant for every response variable with both methods, the differences were, in most cases, a relatively small proportion of the values recorded. In addition, the differences were generally smaller than the precision level. For example, the difference in total canopy cover between the two teams was $5 \%$ of the cover for the visual-estimate method and $8 \%$ of the cover for the pointfrequency method, whereas relative precision was $\sim 15 \%$ over all vegetation types for both methods. The exception to this pattern was species richness. With the visual-estimate method, the team values differed by 1.2 species per subsample, which is $15 \%$ of the mean and less than the relative precision overall or for any vegetation type. In contrast, with the point-frequency method, the team values differed by 2.0 species, which was $40 \%$ of the average richness of a subsample and approximately twice the relative precision for all vegetation types except badlands. Thus, the point-frequency method not only captured fewer species, but also was less repeatable in the number of species it captured.

We were surprised at the high repeatability of the visualestimate method, but our results are consistent with two other recent studies (Kercher et al. 2003; Helm and Mead 2004). We believe our high repeatability is attributable to two factors. First, estimates of graminoid cover were made more repeatable by using the Daubenmire (1959) method of estimating the cover of an individual plant based on the polygon encompassing the plant's outermost points, compared with the other visual-estimate method (sometimes referred to as foliar cover) of estimating the amount of light intercepted by the foliage of a plant. Second, having two observers working together on each quadrat made it necessary for those two observers to agree on a value. This moderated the tendencies of some individuals to estimate high or low compared with others (Klimeš 2003). However, obtaining similar cover estimates over many years of sampling, particularly when there is a large turnover among observers, would require explicit written instructions and photographic examples of vegetation encountered in the field for training. These training documents would reduce personal biases, such as those we encountered early in training: the first visual estimates of the cover of an individual grass species in a quadrat ranged from $2 \%$ to $30 \%$.

Repeatability of both methods would be improved beyond our rate if two issues were addressed. First is the issue of "tape creep," in which rough terrain or dense woody vegetation near ground level made accurate replacement of the transects difficult. In these situations, two markers at the ends of the transects were insufficient to accurately reset the sampling lines. Although putting in a larger number of markers along the transect is an obvious solution, this must be balanced against the objections of managers to having large numbers of markers because of visual impact and potential injury to stock and wildlife. The second, and more difficult, issue is species identification, which was responsible for species pseudoturn- 
over. There were definite cases of different identification of an individual species between teams, as well as identification by one team and "unknown" status by another. There were also instances in which one team was more discriminating in species identification than was the other; that is, the number of species recorded by one team, but not the other, was highly uneven between teams. More training of individuals on recording teams and requiring at least one highly skilled botanist on a team will help reduce these problems (Scott and Hallam 2003), but there will always be variability in experience and skill level of observers. Additional measures, such as referring to a cumulative list of a plot's previous years' species, when sampling, could increase the likelihood that species will be identified the same way from year to year.

\section{Efficiency}

The greatest difference between the two sampling methods, as we implemented them, was efficiency, both in terms of the time to complete the sampling and in the number of species captured by the method. The point-frequency method was clearly more efficient, in terms of time, particularly in species-rich vegetation or where identifying species was difficult (e.g., prairie dog towns), and the time it took was more predictable. On the other hand, the visual-estimate method was clearly better at capturing more species quantitatively in all but the least-diverse vegetation type (herbaceous riparian, in this study). Even if the number of points in the point-frequency method were doubled to approximately equal the amount of time spent sampling with the visualestimate method, the shape of species-accumulation curves from a variety of vegetation types (Fig. 3) suggests that the pointfrequency method would still not achieve the species numbers that the visual-estimate method did.

Determining whether extra time to capture more species is worth the expense, however, depends on whether the priority is overall species richness or the abundance of rarer individual species. For the former, the visual-estimate method (or at least quadrat-based species counts) is more efficient. For the latter, neither method, as we employed them, is likely to be useful because the error on their cover measurements is so large relative to their mean. Also, the difference in completion time between the two methods may be substantial enough to significantly affect the number of plots that could be sampled in a given field season, but that would depend on travel time to and from sampling sites. If that travel time is large, an extra hour sampling at the site (because four observers usually work on a single plot) may be insignificant.

\section{IMPLICATIONS}

Our results show that the visual-estimate method of measuring plant canopy cover is just as, if not more, repeatable than a point-frequency method, even without the use of cover classes. However, the longer amount of time required by this visualestimate method could reduce statistical power of a vegetation sampling or monitoring design when sampling resources are limited. This study adds to a history of studies comparing vegetation measurement methods in rangelands (e.g., Kinsinger et al. 1960; Poissonet et al. 1973; Floyd and Anderson 1987; Stohlgren et al. 1998; Prosser et al. 2003). As emphasis of many public land management agencies shifts from production to biodiversity management, and as the public requests more information on the status and trends of the health of public lands, vegetation monitoring methods on these lands must be developed to meet these shifting needs. Easily accessible, quantitative data on the precision, repeatability, and efficiency of a variety of methods in a variety of rangeland types enable those embarking on a vegetation sampling or monitoring project to more quickly narrow down their methodology options. In addition, this literature provides a firm foundation for the defensibility of various methods, which is crucial for agencies facing strong scrutiny of the data used to guide their land management decisions.

\section{ACKNOWLEDGMENTS}

We would like to thank M. Bynum, L. Divine, P. Graeve, M. Jakobek, K. Johnson, B. Kobza, and T. Schmitt for field work; G. Jones for funding and field work at FOLA; J. Brumm for GIS support; D. Buhl for statistical support; and D. Manier, A. Woodward, J. Keeley, Jeffrey Beck, Justin Derner, and two anonymous reviewers for helpful comments on earlier drafts of this manuscript.

\section{LITERATURE CITED}

BråkenHIELM, S., AND Q. Liu. 1995. Comparison of field methods in vegetation monitoring. Water, Air, and Soil Pollution 79:75-87.

Bray, J. R., And J. T. CuRtis. 1957. An ordination of the upland forest communities of southern Wisconsin. Ecological Monographs 27:325-349.

Caughlan, L., and K. L. Oakley. 2001. Cost considerations for long-term ecological monitoring. Ecological Indicators 1:123-134.

Cheal, D. 2008. Repeatability of cover estimates? Ecological Management and Restoration 9:67-68.

CoLweLL, R. K. 2005. EstimateS: statistical estimation of species richness and shared species from samples, Version 7.5 [computer program]. User's guide and application. Available at: http://purl.oclc.org/estimates. Accessed 20 March 2006.

DaubenmiRE, R. F. 1959. A canopy-coverage method of vegetational analysis. Northwest Science 33:43-64.

Elzinga, C. L., D. W. Salzer, and J. W. Willoughby. 1998. Measuring and monitoring plant populations. Denver, CO, USA: Bureau of Land Management, Technical Reference 1730-1. $477 \mathrm{p}$.

Floyd, D. A., and J. E. Anderson. 1987. A comparison of three methods for estimating plant cover. Journal of Ecology 75:221-228.

Gotrryd, A., And R. I. C. Hanselt. 1985. The impact of observer bias on multivariate analyses of vegetation structure. Oikos 45:223-234.

Hanson, H. C. 1950. Ecology of the grassland. II. Botanical Review 16:283-360.

Helm, D. J., and B. R. Mead. 2004. Reproducibility of vegetation cover estimates in south-central Alaskan forests. Journal of Vegetation Science 15: $33-40$.

Herrick, J. E., J. W. Van Zee, K. M. Havstad, L. M. Burkett, and W. G. Whitford. 2005. Monitoring manual for grassland, shrubland and savanna ecosystems: design, supplementary methods and interpretation. Volume 2. Las Cruces, NM, USA: US Department of Agriculture, Agricultural Research Service, Jornada Experimental Range. $200 \mathrm{p}$.

HoRn, H. 1966. Measurement of "overlap" in comparative ecological studies. American Naturalist 100:419-424.

Kercher, S. M., C. B. Frieswyk, and J. B. Zedler. 2003. Effects of sampling teams and estimation methods on the assessment of plant cover. Journal of Vegetation Science 14:899-906. 
Kinsinger, F. E., R. E. Eckert, and P. O. Currie. 1960. A comparison of the lineinterception, variable-plot and loop methods as used to measure shrub-crown cover. Journal of Range Management 13:17-21.

KLIMEŠ, L. 2003. Scale-dependent variation in visual estimates of grassland plant cover. Journal of Vegetation Science 14:815-821.

MagurRan, A. E. 1988. Ecological diversity and its measurement. Princeton, NJ, USA: Princeton University Press. $179 p$.

NILSSON, I. N., AND S. G. NiLSSON. 1985. Experimental estimates of census efficiency and pseudoturnover on islands: error trend and between-observer variation when recording vascular plants. Journal of Ecology 73:65-70.

Poissonet, P. S., J. A. Poissonet, M. P. Godron, and G. A. Long. 1973. A comparison of sampling methods in dense herbaceous pasture. Journal of Range Management 26:65-67.

Prosser, C. W., K. M. Skinner, and K. K. Sedivec. 2003. Comparison of two techniques for monitoring vegetation on military lands. Journal of Range Management 56:446-454.

Sargeant, G. A., and M. W. Oehler, Sr. 2007. Dynamics of newly established elk populations. Journal of Wildlife Management 71:1141-1148.
SAS [Computer Program]. 2004. SAS OnlineDoc 9.1.2. Cary, NC, USA: SAS Institute Inc. Scot, W. A., and C. J. Hallam. 2003. Assessing species misidentification rates through quality assurance of vegetation monitoring. Plant Ecology 165:101-115.

Stampfl, A. 1991. Accurate determination of vegetational change in meadows by successive point quadrat analysis. Vegetatio 96:185-194.

Stohlgren, T. J., K. A. Bull, and Y. Otsuki. 1998. Comparison of rangeland vegetation sampling techniques in the central grasslands. Journal of Range Management 51:164-172.

Symstad, A. J., C. L. Wienk, and A. Thorstenson. 2006. Field-based evaluation of two herbaceous plant community sampling methods for long-term monitoring in northern Great Plains national parks. Helena, MT, USA: US Geological Survey, Open-File Report 2006-1282. 99 p.

us Department of the Interior, National Park Service. 2003. Fire monitoring handbook. Boise, ID, USA: Fire Management Program Center, National Interagency Fire Center. 274 p.

Vanha-Majamaa, I., M. Salemaa, S. Tuominen, and K. Mikkola. 2000. Digitized photographs in vegetation analysis-a comparison of cover estimates. Applied Vegetation Science 3:89-94. 